photosynthetic bacteria, however, its existence appears to be confined to the Mycobacteriaceae (Goodwin \& Jamikorn, 1956).

The effect of diphenylamine on species of Chlorobium is qualitatively similar to its effect on Rhodospirillum rubrum (Goodwin \& Osman, 1954) and a species of Chromatium (Goodwin \& Land, unpublished observations), and different from its effect on Rhodopseudomonas spheroides (Goodwin, Land \& Osman, 1955) and the algae Chlorella vulgaris (Goodwin, 1954) and Euglena gracilis v. bacillaris (Goodwin \& Jamikorn, 1954), where growth and carotenoid synthesis are equally inhibited and there is no stimulation of synthesis of phytofluene etc.

\section{SUMMARY}

1. Chlorobium limicola, Chlorobium thiosulphatophilum and an unnamed halophilic species produce $\gamma$-carotene as the main carotenoid pigment $(85 \%$ of the total). Rubixanthin also occurs in the first two species (10-15\% of the total). Traces of pro- $\gamma$ carotene and three unidentified pigments also exist; the last may be artifacts.

2. Diphenylamine strongly inhibits the synthesis of $\gamma$-carotene and its derivatives, but only slightly stimulates the production of phytoene, phytofluene and $\zeta$-carotene.

We thank the Medical Research Council for a grant toward laboratory expenses (T.W.G.) and the University of Liverpool for a fellowship (D.G.L.).

\section{REFERENCES}

Barer, R. (1955). Science, 121, 709.

Garton, G. A., Goodwin, T. W. \& Lijinsky, W. (1951). Biochem. J. 48, 154.
Goodwin, T. W. (1952a). Biochem. J. 50, 550.

Goodwin, T. W. (1952b). The Comparative Biochemistry of the Carotenoids. London: Chapman and Hall, Ltd.

Goodwin, T. W. (1954). Experientia, 10, 213.

Goodwin, T. W. (1956). Biochem. J. 62, 346.

Goodwin, T. W. \& Jamikorn, M. (1954). J. Protozool. 1, 216.

Goodwin, T. W. \& Jamikorn, M. (1956). Biochem. J. 62, 269.

Goodwin, T. W. \& Land, D. G. (1955). Biochem. J. 60, xvii.

Goodwin, T. W., Land, D. G. \& Osman, H. G. (1955). Biochem. J. 59, 491.

Goodwin, T. W. \& Morton, R. A. (1946). Analyst, 71, 15.

Goodwin, T. W. \& Osman, H. G. (1953). Biochem. J. 53, 541.

Goodwin, T. W. \& Osman, G. H. (1954). Biochem. J. 56, 222.

Goodwin, T. W. \& Srisukh, S. (1949). Biochem. J. 45, 263.

Katz, E. \& Wassink, E. C. (1939). Enzymologia, 7, 97.

Kuhn, R. \& Grundmann, C. (1934). Ber. dtsch. Chem. Ges. 67, 339.

Larsen, H. (1952). J. Bact. 64, 187.

Mackinney, G. (1935). J. biol. Chem. 112, 421.

Polgár, A., van Niel, C. B. \& Zechmeister, L. (1944). Arch. Biochem. 5, 243.

Starr, M. P. \& Saperstein, S. (1953). Arch. Biochem. Biophys. 43, 157.

Strain, H. H. (1951). In A Manual of Phycology. Ed. by Smith, G. M. Waltham, Mass: Chronica Botanica Co.

van Niel, C. B. \& Muller, F. M. (1931). Rec. Trav. bot. néerl. 28, 245.

Zechmeister, L. (1944). Chem. Rev. 34, 267.

Zechmeister, L. \& Petracek, F. J. (1952). J. Amer. chem. Soc. 74, 282.

Zechmeister, L. \& Schroeder, W. A. (1942). J. Amer. chem. Soc. 64, 1173.

\title{
Studies on Cholinesterase
}

\section{RETURN OF CHOLINESTERASE ACTIVITY IN THE RAT AFTER INHIBITION BY CARBAMOYL FLUORIDES*}

\author{
BY D. K. MYERS \\ Pharmaco-therapeutic Laboratory of the University of Amsterdam, Amsterdam, Holland
}

(Received 14 September 1955)

Eserine, prostigmine and analogous carbamates have, in contrast to the organophosphorus derivatives, generally been regarded as reversible inhibitors of the cholinesterases. However, a detailed study of the mechanism of inhibition of the pseudocholinesterase by a compound of this type (Myers, 1952) showed that the reaction was similar to that

* Part 9: Myers (1953). proposed for the inhibition by the organophosphorus derivatives (cf. Burgen, 1949; Burgen \& Hobbiger, 1951; Wilson, 1951, 1952; Aldridge, 1950, 1953; Aldridge \& Davison, $1952 a, 1953)$. The inhibited enzyme is considered to be a dimethylcarbamoyl derivative for an inhibitor such as prostigmine (cf. Myers, 1954) and therefore analogous to the proposed dialkyl phosphoryl derivatives of the esterases. This conclusion was 
confirmed by the finding that $N N$-dimethylcarbamoyl fluoride, like the dialkyl phosphonofluoridates, is also a potent inhibitor of the cholinesterases (Myers \& Kemp, 1954).

On the basis of this theory, it would be expected that the return of the cholinesterase activity after inhibition in vivo should follow an exponential curve with the kinetics of a first-order reaction. This appears to be true for the pseudocholinesterase after inhibition by diethyl $p$-nitrophenyl phosphate (E600) and analogues, but the activity of the pseudocholinesterase of brain returns much more slowly than that of other tissues (Davison, 1953, 1955). Moreover, the recovery of the true cholinesterase activity exhibits two distinct phases after inhibition by the organophosphorus derivatives; $60 \%$ of the activity returned much more rapidly than the remainder both in vitro and in vivo. Davison $(1953,1955)$ suggested that there are two types of true cholinesterase in the same tissue, differing in the stability of their dialkyl phosphoryl derivatives. Since the reaction of the carbamoyl fluorides and of the organophosphorus derivatives with the cholinesterases were presumed to follow the same pathways, it seemed interesting to investigate the return of cholinesterase activity in the rat after inhibition by carbamoyl fluorides. This investigation was carried out in the same way as has been described by Davison $(1953,1955)$ for the organophosphorus derivatives.

\section{METHODS}

As in previous investigations, the esterase activity was measured manometrically by the Warburg technique at $37.5^{\circ}$ and $\mathrm{pH} 7.4$ in a medium containing $0.025 \mathrm{M}-\mathrm{NaHCO}_{3}$ and saturated with $\mathrm{CO}_{2}+\mathrm{N}_{2}(5: 95)(\nabla / v)$. True cholinesterase activity was measured with $0.03 \mathrm{M}$ acetyl $-\beta$ methylcholine (Mendel, Mundell \& Rudney, 1943) and pseudocholinesterase activity with $0.02 \mathrm{M}$ butyrylcholine as substrate (Cohen, Kalsbeek \& Warringa, 1949). The aliesterases of serum and brain were determined with a $0.2 \%$ $(\mathrm{v} / \mathrm{v})$ emulsion of tributyrin stabilized with $0.1 \%$ gum acacia (final concentrations). Although the activities of these two ali-esterases are measured in the same way, it should be noted that the ali-esterase of serum is a different enzyme from that found in brain (Mendel \& Myers, 1953; Mendel, Myers, Uyldert, Ruys \& Bruyn, 1953; Myers \& Kemp, 1954). The cholinesterases present in serum, on the other hand, appear to be identical with those found in other tissues (Ord \& Thompson, 1952; Myers, 1953; Davison, 1953).

The inhibitors used were $N N$-dimethylcarbamoyl fluoride and $N N$-diethylcarbamoyl fluoride. Both compounds are colourless liquids, moderately soluble in water and stable in aqueous solution (Schrader, 1947). These compounds were injected in aqueous solution intraperitoneally into male rats weighing approx. $250 \mathrm{~g}$. After various intervals of time the rats were killed under ether narcosis, the blood was collected from the carotid artery, the brains were removed and ground quickly with 4 vol. of cold water. The doses of these inhibitors were selected so as to produce fibrillary twitching. of the muscles and other symptoms of acetylcholine accumulation due to true cholinesterase inhibition within a short time after the injection. Five of the forty-five rats injected with $5 \mathrm{mg} . / \mathrm{kg}$. of the dimethylcarbamoyl fluoride died 6-10 min. after the injection; the results for these animals were not included. In confirmation of the results obtained by Gunter \& Mendel (1945), Koelle \& Gilman (1946), Hawkins \& Mendel (1947), Nachmansohn \& Feld (1947) and Freedman \& Himwich (1948), it was noted that the brains of the animals which succumbed to the inhibition contained less than $10 \%$ of their normal cholinesterase activity, whereas the brains of the surviving animals contained approx. $25 \%$ of the normal activity at this time.

Since the inhibition of the esterases by diethylcarbamoyl fluoride proved to be almost irreversible, it was not necessary to take any special precautions to minimize the reversal of the inhibition during the determination of the residual esterase activity. The inhibition by the dimethyl analogue, however, was more readily reversible. The brain suspension was, therefore, held at $2^{\circ}$ until the esterase activity could be determined, this determination being carried out on the same day. Further, the volume of the reaction mixture in the Warburg vessels was restricted to $2 \mathrm{ml}$. to minimize the dilution of the brain, and the esterase activity was measured over a period of $20 \mathrm{~min}$. after previous equilibration of the vessels for $15 \mathrm{~min}$., in order to minimize the time of incubation at $37.5^{\circ}$ in vitro. The experiments with serum were carried out in the same way but the serum was placed in the side arm of the Warburg vessel; this eliminated any dilution effects up to the time when the esterase activity was measured. This procedure was apparently fairly successful in minimizing the in vitro recovery of the inhibited esterases, since the cholinesterase of brain appeared to be $75-95 \%$ inhibited at a time when the symptoms of cholinesterase inhibition in the animal were at a maximum; these values are only slightly lower than those obtained with an irreversible inhibitor (cf. Nachmansohn \& Feld, 1947; Freedman \& Himwich, 1948). The small errors caused by a small reversal of the existing inhibition in vitro do not, in any case, have any influence on the estimation of the rate of recovery, since the time of incubation at $37.5^{\circ}$ in vitro was identical in all experiments and thus the error introduced should be the same in all cases.

The rate of recovery of the esterase activity after inhibition in vivo can be estimated from the exponential curve obtained when the esterase activity is plotted against the time after injection of the inhibitor. More accurate data are obtained when the logarithm of the percentage inhibition is plotted against the time (cf. Aldridge, 1953; Davison, 1953, 1955). The half-life of the enzyme-inhibitor complex can be read from the straight line obtained and the first-order constant $\left(k_{\mathrm{p}}\right)$ for the decomposition of the enzyme-inhibitor complex calculated as $k_{\mathrm{D}}=0 \cdot 693 /$ halflife. In the present investigation it was found that the esterases, despite their difference in sensitivity to the inhibitors (Fig. 1), all began to recover exponentially at the same time, i.e. $10 \mathrm{~min}$. after injection of the dimethylcarbamoyl fluoride and $3 \mathrm{hr}$. after injection of the diethyl analogue. The absence of a significant lag phase with one or two of the esterases and the large differences in the rate 
of recovery of the various esterases indicate that the rate of recovery is not complicated by the presence of appreciable amounts of free inhibitor in the animal after these periods of time.

\section{RESULTS}

Fig. 1 shows the relation between the inhibitor concentration and the percentage inhibition of the esterase activities after incubation for $30 \mathrm{~min}$. at

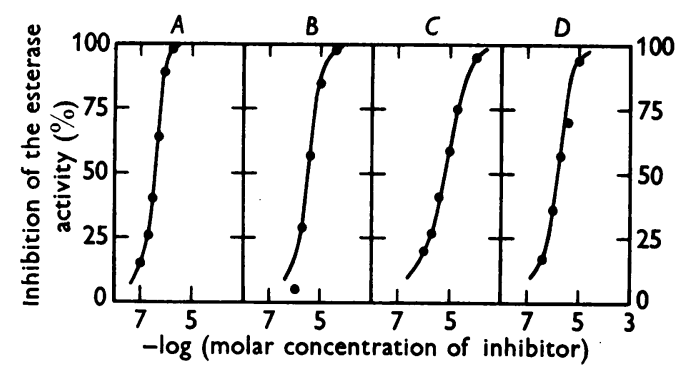

Fig. 1. Inhibition of the esterases of the rat by $N N$ dimethylcarbamoyl fluoride in vitro. The enzyme preparations were incubated for $30 \mathrm{~min}$. at $37.5^{\circ}$ and $\mathrm{pH} 7 \cdot 4$ with various concentrations of the inhibitor before measuring the residual esterase activity. Results are given for: $A$, the true cholinesterase of rat brain; $B$, the pseudocholinesterase of rat serum; $C$ the ali-esterase of rat brain; $D$, the ali-esterase of rat serum.

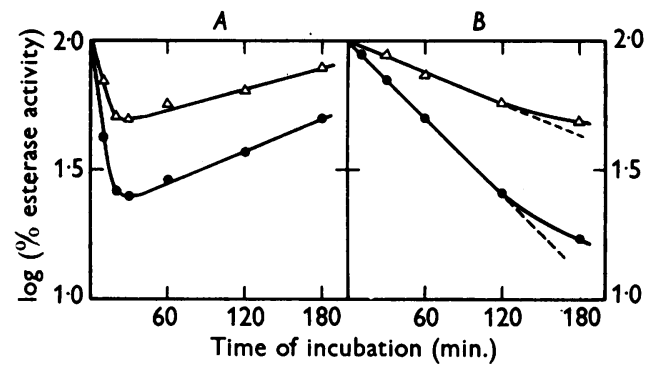

Fig. 2. Progress of the inhibitory reaction between the true cholinesterase of rat brain and the dialkylcarbamoyl fluorides in vitro. Rat-brain suspensions were incubated at $37.5^{\circ}$ and $\mathrm{pH} 7.4$ for various periods of time with a selected concentration of inhibitor before measuring the residual activity of the true cholinesterase. Data are given for: $A, N N$-dimethylcarbamoyl fluoride in concentrations of $4 \times 10^{-7} \mathrm{M}(\Delta)$ and $1 \times 10^{-6} \mathrm{M}(O) ; B, N N$. diethylcarbamoyl fluoride in concentrations of $2 \times 10^{-6} \mathrm{M}$ $(\triangle)$ and $1 \times 10^{-5} \mathrm{M}(\mathrm{O})$.

$37 \cdot 5^{\circ}$ with dimethylcarbamoyl fluoride. The curves show no abnormal inflexions and are of the shape expected for a competitive esterase inhibitor (Goldstein, 1944). Similar curves were obtained with the diethylcarbamoyl fluoride.

Fig. 2 shows the progress of the inhibitory reaction between the true cholinesterase of rat brain and the two carbamoyl fluorides after various periods of incubation. The reaction with the dimethyl compound (Fig. 2A) reaches an equilibrium within $30 \mathrm{~min}$., and subsequently some reversal of the inhibition is apparent as the incubation is prolonged. These results are strikingly similar to those reported by Aldridge (1953) for the inhibition of the true cholinesterase of wholerabbit blood by dimethyl $p$-nitrophenyl phosphate; the reversal of the inhibition on prolonged incubation of the reaction mixture is probably due in both cases to destruction of the excess of inhibitor and subsequent recovery of the inhibited enzyme. On the other hand, the inhibition by diethylcarbamoyl fluoride increases continuously for several hours (Fig. 2B); similar results have been obtained for the inhibition of the true cholinesterase by diethyl $p$-nitrophenyl phosphate (Aldridge, 1950, 1953; Aldridge \& Davison, 1952 $a$ ).

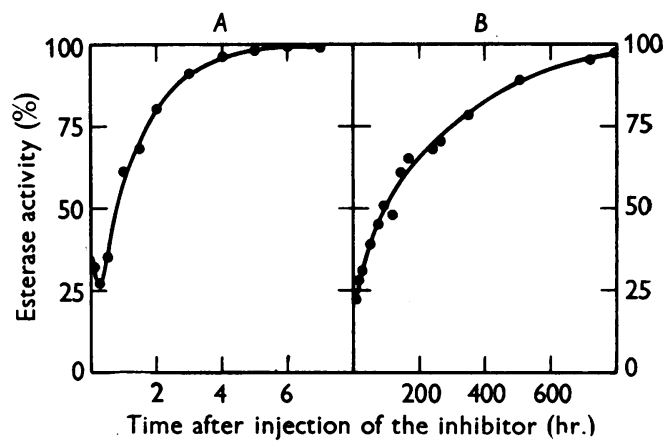

Fig. 3. Return of the activity of the true cholinesterase after inhibition by the dialkylcarbamoyl fluorides in vivo. The results given are those obtained after intraperitoneal injection of: $A, 5 \mathrm{mg}$. of $N N$-dimethylcarbamoyl fluoride/kg.; $B, 40 \mathrm{mg}$. of $N N$-diethylcarbamoyl fluoride/kg. Each point represents the average of individual measurements on two to six rats; further details are given in Table 1.

The return of the true cholinesterase activity in the brain of rats after injection of the carbamoyl fluorides is indicated in Fig. 3. The rates of recovery after inhibition by the dimethyl- and diethyl-carbamoyl fluorides are very similar to the rates of recovery of true cholinesterase activity after inhibition by dimethyl and diethyl $p$-nitrophenyl phosphates respectively (cf. Aldridge, 1953; Davison, 1953, 1955). However, the curve for the recovery of the true cholinesterase of rat brain after inhibition by the organophosphorus compounds shows a marked inflexion at the point of $60 \%$ activity, the remaining $40 \%$ of the activity being more permanently inhibited (Davison, 1953, 1955). The recovery of the same enzyme after inhibition by the carbamoyl fluorides, on the other 
hand, continues to completion and appears to follow the exponential curve of a first-order reaction (Fig. 3). This supposition was confirmed by the fact that a straight line is obtained when the logarithm of the percentage inhibition is plotted against the time (Fig. 4). From this line, the halflife periods of the inhibited cholinesterase were estimated to be 0.88 and $182 \mathrm{hr}$. after inhibition by the dimethyl- and diethyl-carbamoyl fluorides

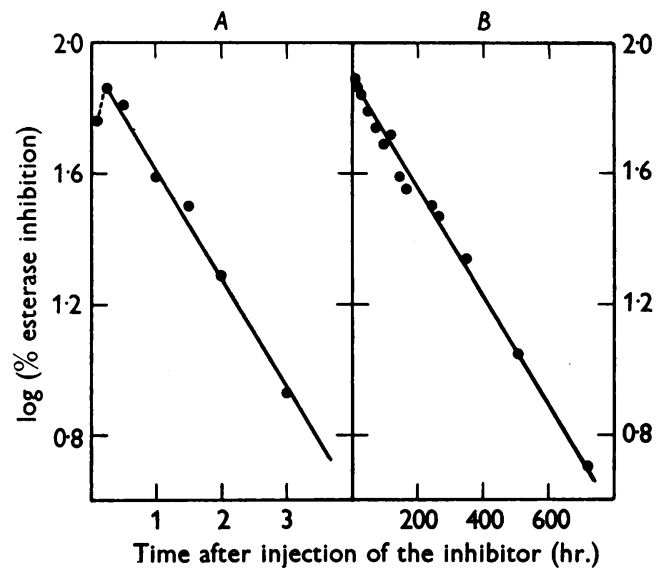

Fig. 4. Return of the activity of the true cholinesterase of rat brain plotted as a first-order reaction. The experimental results are the same as those of Fig. 3 and were obtained after injection of: $A, 5 \mathrm{mg}$. of $N N$-dimethylcarbamoyl fluoride/kg.; $B, 40 \mathrm{mg}$. of $N N$-diethylcarbamoyl fluoride/kg.

respectively. The corresponding first-order constants $\left(k_{\mathrm{D}}\right)$ for the decomposition of the enzymeinhibitor complexes were calculated as $1.3 \times 10^{-2}$ and $6.3 \times 10^{-5} \mathrm{~min}^{-1}$ respectively (Table 1 ). By way of comparison, it might be noted that the first-order constant for the recovery of the true cholinesterase of rabbit erythrocytes after inhibition by dimethyl phosphoryl derivatives is about $8.6 \times 10^{-8} \mathrm{~min}^{-1}$ (Aldridge, 1953).

The results obtained with the other esterase activities of brain and serum after injection of the carbamoyl fluorides are summarized in Table 1 . These results indicate that a structural alteration which increases the stability of the inhibitor also tends to increase the stability of the enzymeinhibitor complex. The inhibition of the true cholinesterase, pseudocholinesterase and serum aliesterase by the diethylcarbamoyl fluoride lasts 200 , 70 and 10 times respectively longer than the inhibition of the same enzymes by the dimethyl analogue. This factor is usually apparent also in the results obtained with the organophosphorusesterase inhibitors (cf. Hobbiger, 1951; Burgen \& Hobbiger, 1951; Wilson, 1952; Aldridge, 1953; Davison, 1955).
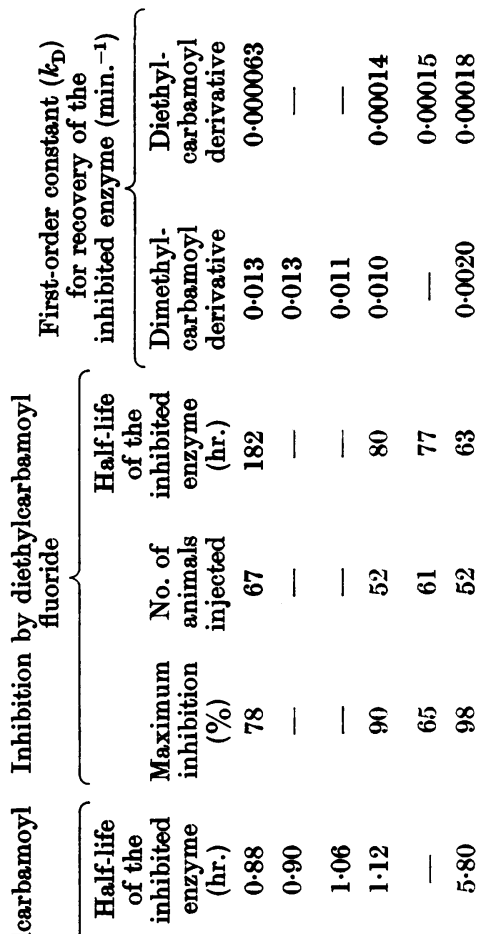

पै

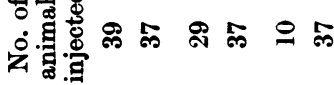

멸.

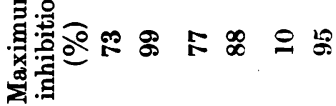

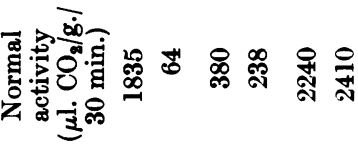

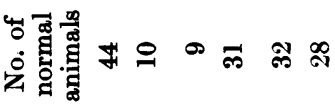

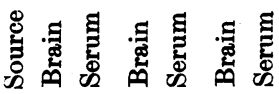


The figures given in Table 1 also show that the true cholinesterase activities of brain and serum recover at approximately the same rate after inhibition by dimethylcarbamoyl fluoride. The same is true for the pseudocholinesterase activities of brain and serum, whereas the pseudocholinesterase activity of the brain recovers much more slowly than that of serum and other tissues after inhibition by the organophosphorus derivatives (Davison, 1953, 1955).

\section{DISCUSSION}

The effect of the carbamoyl fluorides on the cholinesterases resembles that of the organophosphorus derivatives in many respects, as noted above. It seems probable that the enzyme-inhibitor complex can be represented as a dialkylcarbamoyl derivative of the enzyme active centre and that the mechanism of the inhibitory reaction is therefore similar to that proposed for the organophosphorus esterase inhibitors. This conclusion is substantiated by the results of a previous investigation on the prostigmine analogue Ro2-0683 (Myers, 1952), by the structure of the inhibitors used in the present investigation, by the prolonged esterase inhibition observed after injection of diethylcarbamoyl fluoride, and by the fact that the esterase activities recover exponentially with a first-order rate constant that is characteristic of the esterase in question and of the structure of the inhibitor.

The complete reaction between the esterase and inhibitor probably involves several stages, which could be written as follows (cf. Burgen \& Hobbiger, 1951 ; Wilson, 1951 ; Aldridge, 1953):

$$
\mathrm{EH}+\mathrm{I}_{\mathrm{ab}}^{\stackrel{1}{\rightleftharpoons}} \stackrel{\mathrm{l}}{\rightleftharpoons} \mathrm{EH}-\mathrm{I}_{\mathrm{ab}} \rightarrow \mathrm{EI}_{\mathrm{a}}+\mathrm{HI}_{\mathrm{b}}
$$

$$
3
$$

$$
\text { and } \mathrm{EI}_{\mathrm{a}}+\mathrm{H}_{2} \mathrm{O} \rightleftharpoons \mathrm{EI}_{\mathrm{a}}-\mathrm{H}_{2} \mathrm{O} \rightarrow \mathrm{EH}+\mathrm{I}_{\mathrm{a}} \mathrm{OH} \text {, }
$$

where EH is the active esterase, $I_{a b}$ is the intact inhibitor molecule, $I_{\mathrm{a}}$ the dialkylcarbamoyl or dialkyl phosphoryl moiety of the inhibitor and $I_{b}$ the remainder of the inhibitor, in this case fluoride. The Michaelis constant $K_{1}=\left(k_{2}+k_{\mathrm{p}}\right) / k_{1}$, where $k_{1}$ is the rate constant for the formation of enzymeinhibitor complex, $k_{2}$ the rate constant for the reversal of this reaction, and $k_{\mathrm{D}}$ the rate constant for the destruction of the inhibitor by the enzyme (Briggs \& Haldane, 1925; cf. Michaelis \& Menten, 1913). Since the compound $\mathrm{EI}_{\mathrm{a}}$ appears to be the stable form of enzyme-inhibitor complex, the values of $k_{1}$ and $k_{\mathrm{D}}$ might well represent the rate constants for the particular reactions which limit the rates of formation and decomposition respectively of $\mathbf{E I}_{\mathrm{a}}$. However, the intermediary compounds $\mathrm{EH}-\mathrm{I}_{\mathrm{ab}}, \mathrm{EI}_{\mathrm{a}}$ and $\mathrm{EI}_{\mathrm{a}}-\mathrm{H}_{2} \mathrm{O}$ all represent enzyme which is combined with inhibitor and the experimental methods only distinguish inhibited enzyme from the enzyme which is free to react with the substrate. The rate constants for the intermediary reactions involving the conversion of one form of inhibited enzyme into another may therefore never appear in the measured value of $K_{I}$; in this case, the measured value of $k_{1}$ will represent the rate constant for reaction 1 in the scheme given above, $k_{2}$ that for reaction 2 and $k_{\mathrm{D}}$ the rate constant for reaction 3 .

The values of $k_{\mathrm{D}}$ and $k_{1}$ have been measured for the reactions between the cholinesterases and a number of organophosphorus derivatives (Aldridge \& Davison, 1952 a, 1953; Aldridge, 1953; Davison, $1953,1955)$. The comparable values of $k_{\mathrm{D}}$ for the four esterases and the two carbamoyl fluorides tested in the present investigation are given in Table 1. The initial inhibitory reaction between the esterases and the carbamoyl fluorides is complicated by the instability of the inhibitors in the reaction mixtures containing brain or serum; however, the initial reaction between the true cholinesterase of rat brain and diethyl carbamoyl fluoride (Fig. $2 B$ ) does seem to be pseudo-monomolecular, as would be expected for a reaction of the form

$$
\mathbf{E}+\mathrm{I} \rightarrow \mathbf{E I},
$$

where the inhibitor is present in large excess. This would indicate that the value of $k_{2}+k_{\mathrm{D}}$ must be small; $k_{1}$ can therefore be determined from the equation $k_{1}=-\ln a / I t$, where $a$ represents the fractional enzyme activity, $I$ the molar concentration of the inhibitor and $t$ the time of incubation (cf. Aldridge, 1950; Aldridge \& Davison, 1952b). In the case given above $k_{1}=1.2 \times 10^{3} 1 . \mathrm{mol}^{-1} \mathrm{~min} . .^{-1}$, and therefore

$$
K_{\mathrm{I}}=\left(k_{2}+k_{\mathrm{D}}\right) k_{1} \geqslant k_{\mathrm{D}} / k_{1}=5 \times 10^{-8} \mathrm{~mol} . \mathrm{l}^{-1} \text {. }
$$

Similar calculations for the initial rate of the reaction between the true cholinesterase of rat brain and dimethylcarbamoyl fluoride (Fig. 2 $A$ ) indicate that $k_{1}$ must have a value of

$$
1 \cdot 0-1.5 \times 10^{5} 1 . \mathrm{mol}^{-1} \mathrm{~min} .^{-1}
$$

and therefore that $K_{1} \geqslant 10^{-7} \mathrm{~mol} . \mathrm{l}^{-1}$.

These values for $K_{\mathrm{I}}$ can be regarded only as minimum estimates, since there is no experimental proof for the assumption that $k_{2}$ is very small in comparison with $k_{\mathrm{D}}$ in the carbamoyl fluorides. An analysis of the rate constants for the reaction between the pseudocholinesterase of human serum and the prostigmine analogue Ro2-0683 showed that the value of $K_{1}$ was equal to $k_{\mathrm{p}} / k_{1}$ in this case. However, according to the present concept, the active centres of both cholinesterases possess an anionic site which increases the affinity of these 
enzymes for choline esters and structurally related inhibitors (cf. Myers, 1951; Bergmann \& Segal, 1954); thus it is conceivable that $k_{2}$ might have a negligible value only when the inhibitor or substrate contains a cationic ammonium group in a suitable position for combining with the anionic site of the active centre of the cholinesterases. This is true for prostigmine and its analogue Ro2-0683, but not for the carbamoyl fluorides. A fact that does not support this suggestion is that it is possible to obtain $50 \%$ inhibition of the true cholinesterase of rat brain with $4 \times 10^{-7} \mathrm{M}$ dimethylcarbamoyl fluoride Fig. 1 (Myers \& Kemp, 1954); since this represents the maximum possible value of $K_{\mathrm{r}}$ and the minimum value calculated above is about $1 \times 10^{-7} \mathrm{M}$, it is evident that $k_{2}$ could not in any case be much greater than $k_{\mathrm{D}}$. Similarly, Aldridge (1950) and Aldridge \& Davison $(1952 b)$ were not able to obtain evidence for reversal of the inhibition by reaction 2 in experiments with organophosphorus derivatives which did not contain a cationic ammonium group.

The only marked dissimilarity between the carbamoyl fluorides and the organophosphorus derivatives in their effects on the cholinesterase appears in the rate of recovery of the cholinesterases of the brain after inhibition by these compounds. The difference between the rates of recovery of the pseudocholinesterase activities of brain and serum and the difference in the rates of recovery of the two fractions of the true cholinesterase activity in the brain observed after inhibition by the organophosphorus derivatives (Davison, 1953, 1955) fail to appear after inhibition by the carbamoyl fluorides.

If there are two forms of the true cholinesterase in the same tissue, and two forms of the pseudocholinesterase in different tissues of the same animal, as suggested by Davison $(1953,1955)$, it. is evident that the differences between the two forms must be very small. Apparently both forms of the same enzyme react at the same rate with carbamoyl or with organophosphorus derivatives; there are no marked differences in the sensitivity to the inhibitors (Ord \& Thompson, 1950, 1952; Davison, 1953) and no abnormal inflexions are observed in the curves obtained when the percentage inhibition of the total true cholinesterase activity of brain is plotted against the concentration of the inhibitor. Further, the relative rate of hydrolysis of various choline esters appears to be identical, even when the rate of recovery after inhibition by organophosphorus derivatives is different (Ord \& Thompson, 1952; Davison, 1953). These results, together with the observations made in the present investigation, all suggest that the structure of the enzyme active centre is identical for the two hypothetical forms of the enzyme in question. It seems probable, therefore, that any difference between the two forms of the true cholinesterase or of the pseudocholinesterase must be ascribed to groups on the enzyme surface adjacent to the enzyme active centre rather than to the enzyme active centres themselves.

In this connexion it might be noted that the hydrolytic activity of the esterases seems to be due to an imidazole group, probably a histidine residue (Wilson \& Bergmann, 1950; Wilson, 1952 ; WagnerJauregg \& Hackley, 1953; Weil, James \& Buchert, 1953; Weil \& Seibles, 1955). The organophosphorus derivatives, the carbamoyl derivatives and the carboxylic acid esters, which serve as substrates, all presumably react with this imidazole group in the same way. It is assumed at present that the acylhistidine derivatives, which are formed during the reaction with carboxylic acid esters (e.g. acetylcholine), undergo a spontaneous hydrolysis without further intramolecular rearrangement. In this case it might logically be assumed that the carbamoylhistidine derivatives behave similarly to the acyl derivatives, since they have a similar structure. However, the dialkyl phosphoryl derivatives of the enzyme active centre may subsequently undergo a partial intramolecular rearrangement whereby the dialkyl phosphoryl group is transferred to a serine residue (Wagner-Jauregg \& Hackley, 1953; Schaffer, May \& Summerson, 1953, 1954; Oosterbaan, Kunst \& Cohen, 1955). We suspect that the difference in the rate of recovery of the two fractions of the true cholinesterase activity after inhibition by the organophosphorus derivatives is due to the existence of these two forms of dialkyl phosphorylated enzyme.

Since the dialkyl phosphoryl serine derivative appears to be considerably more stable than the histidine derivative which is formed initially (cf. Schaffer et al. 1953, 1954; Cunningham, 1954; Jandorf, Crowell \& Levin, 1955; Hobbiger, 1955), it seems likely that the more permanently inhibited portion of the true cholinesterase activity probably represents a dialkyl phosphoryl serine derivative. The readily reversible portion of the activity might then represent the dialkyl phosphoryl histidine derivative. In this case, it would be necessary to assume that the transfer of the dialkyl phosphoryl group to the serine residue is prevented by shielding or absence of the erine residue adjacent to the enzyme active centre.

A different explanation for the disparity in the rates of recovery of the two fractions of true cholinesterase activity in rat-brain preparations after inhibition by organophosphorus derivatives is suggested by the effects of proteolytic enzymes observed by Davison (1955). The slowly reversible portion of the true cholinesterase activity of brain was much more resistant than the rapidly reversible 
portion to the action of pepsin. Moreover, the rate of recovery of pseudocholinesterase after inhibition by organophosphorus derivatives was increased in the presence of trypsin. It is possible, therefore, that the rates of recovery of the true cholinesterase and pseudocholinesterase activities in vivo and in crude tissue preparations in vitro depend partly on the action of the intracellular proteolytic enzymes, namely cathepsins. It might then be assumed that the cholinesterase activities of brain which recover slowly after inhibition by the organophosphorus derivatives represent lipoprotein complexes which are not accessible to the action of these proteolytic enzymes and which recover at the normal rate for the dialkyl phosphoryl serine derivatives.

The experimental data available at present do not allow a decision on the validity of the two explanations suggested. However, in view of the considerations given above, the conclusion that the slowly reversible and the rapidly reversible fractions of the cholinesterase activities are due to different enzymes does not seem to be justified. Both fractions appear to possess identical active centres and recover their activity at the same rate after inhibition by the carbamoyl fluorides; where differences in the rate of recovery of the two fractions are observed, they could be ascribed, directly or indirectly, to migration of the inhibitory dialkyl phosphoryl group from the enzyme active centre to an adjacent serine residue.

\section{SUMMARY}

1. The initial inhibitory reaction between the true cholinesterase of rat brain and $N N$-dimethylor $N N$-diethyl-carbamoyl fluoride is similar to that observed with the organophosphorus esterase inhibitors. The reaction with the dimethyl compound reaches an equilibrium quickly, whereas the inhibition by the diethyl compound increases continuously for several hours.

2. After injection of the carbamoyl fluorides into rats, the esterase activities recover completely; the recovery follows the exponential curve of a first-order reaction. The rate of recovery is independent of the tissue in which the esterase is located but differs from one esterase to another. All four esterases investigated recovered more slowly after inhibition by the diethyl compound than after inhibition by the dimethyl compound.

3. An attempt was made to analyse the reaction of the inhibitors with cholinesterase in terrns of the rate constants involved in the Michaelis constant $K_{1}=\left(k_{2}+k_{\mathrm{D}}\right) / k_{1}$ (cf. Briggs \& Haldane, 1925). It is suggested that $k_{2}$ may not have a large value.

4. The results support the conclusion that the mechanism by which the carbamoyl derivatives inhibit the esterases is sinilar to that proposed for the organophosphorus derivatives. The differences in the return of the cholinesterase activity after inhibition by the carbamoyl and by the organophosphorus derivatives are discussed in terms of the structure of the enzyme active centre.

The author is indebted to Miss E. G. L. Simons for technical assistance and to Dr G. Schrader, Elberfeld, for samples of $N N$-dimethylcarbamoyl fluoride and $N N$ diethylcarbamoyl fluoride.

\section{REFERENCES}

Aldridge, W. N. (1950). Biochem. J. 46, 451.

Aldridge, W. N. (1953). Biochem. J. 54, 442.

Aldridge, W. N. \& Davison, A. N. (1952a). Biochem. J. 51, 62.

Aldridge, W. N. \& Davison, A. N. (1952b). Biochem. J. 52, 663.

Aldridge, W. N. \& Davison, A. N. (1953). Biochem. J. 55, 763.

Bergmann, F. \& Segal, R. (1954). Biochem. J. 58, 692.

Briggs, G. E. \& Haldane, J. B. S. (1925). Biochem. J. 19, 338.

Burgen, A. S. V. (1949).'Brit. J. Pharmacol. 4, 219.

Burgen, A. S. V. \& Hobbiger, F. (1951). Brit. J. Pharmacol. 6, 593.

Cohen, J. A., Kalsbeek, F. \& Warringa, M. G. P. J. (1949). Acta brev. neerl. Physiol. 17, 32.

Cunningham, L. W. (1954). J. biol. Chem. 207, 443.

Davison, A. N. (1953). Biochem. J. 54, 583.

Davison, A. N. (1955). Biochem. J. 60, 339.

Freedman, A. M. \& Himwich, H. E. (1948). Amer. J. Physiol. 153, 121.

Goldstein, A. (1944). J. gen. Physiol. 27, 529.

Gunter, J. M. \& Mendel, B. (1945). Canad. Chem. Metall. 29, 136.

Hawkins, R. D. \& Mendel, B. (1947). Brit. J. Pharmacol. 2, 173.

Hobbiger, F. (1951). Brit. J. Pharmacol. 6, 21.

Hobbiger, F. (1955). Abstr. 3rd Int. Congr. Biochem., Brussels, p. 30.

Jandorf, B. J., Crowell, E. A. \& Levin, A. P. (1955). Fed. Proc. 14, 231.

Koelle, G. B. \& Gilman, A. (1946). J. Pharmacol. 87, 421.

Mendel, B., Mundell, D. B.\& Rudney, H.(1943). Biochem.J. 37, 473.

Mendel, B. \& Myers, D. K. (1953). Biochem. J. 53, xvi.

Mendel, B., Myers, D. K., Uyldert, I. E., Ruys, A. C. \& Bruyn, W. M. de (1953). Brit. J. Pharmacol. 8, 217.

Michaelis, L. \& Menten, M. L. (1913). Biochem. Z. 49, 333.

Myers, D. K. (1951). Arch. Biochem. Biophys. 31, 29.

Myers, D. K. (1952). Biochem. J. 52, 46.

Myers, D. K. (1953). Biochem. J. 55, 67.

Myers, D. K. (1954). Ph.D. thesis: University of Amsterdam.

Myers, D. K. \& Kemp, A., jun. (1954). Nature, Lond., 173, 33.

Nachmansohn, D. \& Feld, E. A. (1947). J. biol. Chem. 171, 715.

Oosterbaan, R. A., Kunst, J. \& Cohen, J. A. (1955). Biochim. biophys. Acta, 16, 299. 
Ord, M. G. \& Thompson, R. H. S. (1950). Biochem. J. 46, 346.

Ord, M. G. \& Thompson, R. H. S. (1952). Biochem. J. 51, 245.

Schaffer, N.K., May, S. C., jun. \& Summerson, W. H. (1953). J. biol. Chem. $202,67$.

Schaffer, N. K., May, S. C., jun. \& Summerson, W. H. (1954). J. biol. Chem. 206, 201.

Schrader, G. (1947). Brit. Intell. Obj. Sub-Comm., Final Report, no. 714.
Wagner-Jauregg, T. \& Hackley, B. E. jun. (1953). J. Amer. chem. Soc. 75, 2125.

Weil, L., James, S. \& Buchert, A. R. (1953). Arch. Biochem. Biophys. 46, 266.

Weil, L. \& Seibles, T. S. (1955). Arch. Biochem. Biophys. $54,368$.

Wilson, I. B. (1951). J. biol. Chem. 190, 111.

Wilson, I. B. (1952). J. biol. Chem. 199, 113.

Wilson, I. B. \& Bergmann, F. (1950). J. biol. Chem. 186, 683.

\title{
The Formation of Glyoxylate and Succinate from Tricarboxylic Acids by Pseudomonas aeruginosa
}

\author{
By H. J. SAZ* AND E. P. HILLARY \\ A.R.C. Unit of Microbiology, Department of Microbiology, The University, Sheffield
}

(Received 22 July 1955)

Campbell, Smith \& Eagles (1953), in a brief note, reported that cell-free extracts of Pseudomonas aeruginosa convert citrate and cis-aconitate, but not isocitrate, into succinate and glyoxylate. The glyoxylate was identified chromatographically as the 2:4-dinitrophenylhydrazone. They also claimed that the reaction was reversible, since incubation of the extract with a mixture of succinate and glyoxylate gave rise to citrate.

The work described below, a preliminary report of which has already been published (Saz, 1954), confirms and extends these findings. Recently, Olson (1954) has shown that Penicillium chrysogenum contains a similar enzyme system.

\section{MATERIALS AND METHODS}

Organisms. Pseudomonas fluorescens strain KB 1 (Kogut \& Podoski, 1953) and a laboratory strain of Ps. aeruginosa were used. Stock cultures were maintained on slopes containing $2 \%$ of Davis New Zealand agar and $10 \%(v / v)$ of yeast autolysate (Barker \& Beck, 1942). For use the organisms were cultured as follows: Pyrex penicillin culture flasks containing $300 \mathrm{ml}$. of $10 \%(\mathrm{v} / \mathrm{v})$ yeast autolysate were inoculated with $1 \mathrm{ml}$. of a suspension prepared by emulsifying the overnight growth on a slope in $4 \mathrm{ml}$. of sterile distilled water. The flasks were incubated for $20 \mathrm{hr}$. at $25^{\circ}$ on a reciprocating shaking machine. The cells were washed thrice in distilled water before use. Stock cultures were maintained on agar slopes.

Reagents. Sodium glyoxylate was synthesized as described by Weissbach \& Sprinson (1953), and the product assayed for glyoxylic acid by the bisulphitebinding method of Long (1942) with the correction factor

* Post-Doctorate Fellow of the National Foundation for Infantile Paralysis. Present address: Department of Pharmacology, School of Medicine, Louisiana State University, New Orleans 12, Louisiana, U.S.A. recommended by this author. $( \pm)$-isoCitrate was prepared by alkaline hydrolysis of trichloromethylparaconic acid. (+)-isoCitric acid was a sample isolated from blackberry leaves and generously supplied by Professor H. A. Krebs. An aqueous extract of boiled brewer's yeast was prepared by suspending $1 \mathrm{~g}$. of dried brewer's yeast (prepared from yeast obtained from Tennant Bros. Ltd., Sheffield) in $10 \mathrm{ml}$. of distilled water and heating for $10 \mathrm{~min}$. in a boiling-water bath with occasional stirring. The suspension was then cooled in an ice bath and clarified by centrifuging. The clear brownish supernatant so obtained was stored at $-20^{\circ}$. Ashed boiled brewer's yeast was prepared by evaporating a sample in a porcelain crucible; when the sample was dry the crucible was closed with a loosely fitting lid and heated for $1 \mathrm{hr}$. over a Bunsen burner. The cooled residue was suspended in a volume of distilled water equal to the volume of the sample of boiled brewer's yeast taken. All other reagents were of A.R. quality and obtained commercially.

Analytical methods. Paper-partition chromatography of 2:4-dinitrophenylhydrazones was carried out by the method of Cavallini, Frontali \& Toschi (1949) with Whatman no. 1 filter paper. The papers were developed by the descending method, with $n$-butanol saturated with water as the solvent. Glyoxylate was estimated by the method for 'total keto acids' devised by Friedemann \& Haugen (1943). This was considered justifiable since, as will be shown below, paperpartition chromatography indicated that glyoxylate was the only keto acid produced by the enzyme system. Succinate was estimated either by partition chromatography on ether-washed Celite 545 (Johns-Manville Co. Ltd., Artillery Row, London, S.W. 1) as described by Swim \& Krampitz (1954) or by the enzymic method of Krebs (1937). Citrate was estimated either colorimetrically by the method of Taylor (1953) or chromatographically as described by Swim \& Krampitz (1954).

\section{Enzyme preparations}

'Mickle' extracts. The washed cells were suspended in cold $\left(5^{\circ}\right)$ distilled water $(4 \mathrm{ml} . / \mathrm{g}$. of cell paste) and the suspension shaken in a Mickle disintegrator (Mickle, 1948) 